\title{
Differential responses to selenomethionine supplementation by sex and genotype in healthy adults
}

\author{
Gerald F. Combs Jr ${ }^{1 *}$, Matthew I. Jackson ${ }^{1}$, Jennifer C. Watts ${ }^{1}$, LuAnn K. Johnson ${ }^{1}$, Huawei Zeng ${ }^{1}$, \\ Joseph Idso ${ }^{1}$, Lutz Schomburg ${ }^{2}$, Antonia Hoeg ${ }^{2}$, Carolin S. Hoefig ${ }^{2}$, Emily C. Chiang ${ }^{3}$, David J. Waters ${ }^{3}$, \\ Cindy D. Davis ${ }^{4}$ and John A. Milner ${ }^{4}$ \\ ${ }^{1}$ Grand Forks Human Nutrition Research Center, USDA-ARS, 2420 2nd Avenue North, Stop 9034, Grand Forks, \\ ND, 58202-9034, USA \\ ${ }^{2}$ Institut für Experimentelle Endokrinologie, Berlin, Germany \\ ${ }^{3}$ Gerald P. Murphy Cancer Foundation, West Lafayette, IN, USA \\ ${ }^{4}$ Nutritional Science Research Group, National Cancer Institute, Bethesda, MD, USA
}

(Submitted 10 March 2011 - Final revision received 21 July 2011 - Accepted 21 July 2011 - First published online 22 September 2011)

\begin{abstract}
A year-long intervention trial was conducted to characterise the responses of multiple biomarkers of Se status in healthy American adults to supplemental selenomethionine (SeMet) and to identify factors affecting those responses. A total of 261 men and women were randomised to four doses of Se $(0,50,100$ or $200 \mu \mathrm{g} / \mathrm{d}$ as L-SeMet) for 12 months. Responses of several biomarkers of Se status (plasma Se, serum selenoprotein P (SEPP1), plasma glutathione peroxidase activity (GPX3), buccal cell Se, urinary Se) were determined relative to genotype of four selenoproteins (GPX1, GPX3, SEPP1, selenoprotein 15), dietary Se intake and parameters of single-carbon metabolism. Results showed that supplemental SeMet did not affect GPX3 activity or SEPP1 concentration, but produced significant, dose-dependent increases in the Se contents of plasma, urine and buccal cells, each of which plateaued by 9-12 months and was linearly related to effective Se dose $\left(\mu \mathrm{g} / \mathrm{d}\right.$ per $\left.\mathrm{kg}^{0.75}\right)$. The increase in urinary Se excretion was greater for women than men, and for individuals of the GPX1 679 T/T genotype than for those of the GPX1 $679 \mathrm{C} / \mathrm{C}$ genotype. It is concluded that the most responsive Se-biomarkers in this non-deficient cohort were those related to body Se pools: plasma, buccal cell and urinary Se concentrations. Changes in plasma Se resulted from increases in its non-specific component and were affected by both sex and GPX1 genotype. In a cohort of relatively high Se status, the Se intake

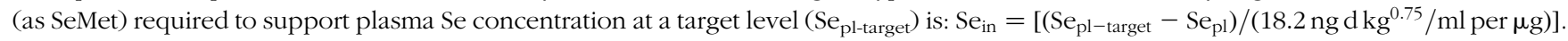

Key words: Selenium: Biomarkers: Selenoprotein P: Glutathione peroxidase: Genotype: Supplementation

Se is an essential mineral nutrient required to support the expression of some twenty-five proteins, each of which contains selenocysteine residues as essential constituents ${ }^{(1)}$. These selenoproteins have diverse functions including antioxidant protection ${ }^{(2)}$, thyroid hormone metabolism ${ }^{(3)}$ and Se transport $^{(4)}$. Selenoprotein expression can be reduced by deprivation of Se. SNP can also affect selenoprotein function, as in the case of cytosolic glutathione peroxidase $(\mathrm{GPX} 1)^{(5)}$. In fact, GPX1 genotype has been associated with cancer risk ${ }^{(6)}$.

High Se status has been associated with reduced cancer risk, and perhaps increased risk of type 2 diabetes. The Nutritional Prevention of Cancer (NPC) Trial showed that increasing Se intake could reduce colon and prostate cancer risk $^{(7)}$, at least for individuals with plasma Se levels $<106 \mathrm{ng} / \mathrm{ml}^{(8)}$. However, the same study indicated that Se-supplemented subjects whose plasma Se levels had increased to $180-200 \mathrm{ng} / \mathrm{ml}$ may have had increased risk of type 2 diabetes $^{(9)}$. Elevated diabetes risk was observed for subjects in the upper quintile of plasma Se $(\geq 137.7 \mathrm{ng} / \mathrm{ml})$ in the third National Health and Examination Survey (NHANES) ${ }^{(10)}$, and among subjects in the upper quartile of plasma Se $(\geq 147 \mathrm{ng} / \mathrm{ml})$ in NHANES $2003-4^{(11)}$. While increased diabetes risk was not found in response to Se-supplementation in the Se and Vitamin E Cancer Prevention Trial ${ }^{(12)}$, neither was protection against cancer detected in that cohort of men of relatively high baseline Se status (mean plasma Se $136.5 \mathrm{ng} / \mathrm{ml}$ ). Chiang et al. ${ }^{(13)}$ rationalised these apparently discrepant results by suggesting that health risk may be associated with Se status according to a 'U'-shaped dose-response curve. They demonstrated that at high dietary exposures Se can cause DNA damage in cells and

Abbreviations: BrdU, bromolated deoxyuridine; GPX, glutathione peroxidase; Hcy, homocysteine; Met, methionine; NHANES, National Health and Examination Survey; NPC, Nutritional Prevention of Cancer; PI, propidium iodide; SeMet, selenomethionine; SEPP1, selenoprotein P. 
induce apoptosis. This may be a mechanism whereby Se exerts its anti-cancer effect; when manifest in non-tumorigenic cells, it may also indicate Se-toxicity.

Such a bi-modal dose-response relationship would suggest that Se may be beneficial for only some individuals, such as those of relatively low Se status and that doses lower than those used previously $\left(200 \mu \mathrm{g} / \mathrm{d}^{(8,12)}\right)$ may be effective. Should this be the case, then food-based approaches using low Se doses would be facilitated by understanding the quantitative relationship of Se intake, biomarkers of Se status and genetic or sex-based modifying factors.

Projecting the Se intake required to support an Se status target requires understanding the relationship of biomarkers of Se status and level of Se intake. Only a few multi-dose studies have been conducted from which to make such projections. Those studies have used various forms of Se supplements, including selenite which produces only minimal increases $(<20 \%)$ in plasma $\mathrm{Se}^{(14-16)}$, unless subjects are of low Se status, i.e. plasma Se $<55 \mathrm{ng} / \mathrm{ml}^{(17)}$. The only plasma proteins into which selenite-Se can be incorporated, selenoprotein P (SEPP1) and GPX3, are maximally expressed in non-deficient subjects. In contrast, the other major supplemental forms, selenomethionine (SeMet) or SeMet-containing supplements (Se-enriched yeast), increase plasma Se in subjects of both low ${ }^{(17)}$ and higher Se status ${ }^{(14-16,18-21)}$, due to the non-specific incorporation of SeMet into proteins in lieu of methionine (Met). Steady-state plasma Se concentrations are not reached for at least 9 months of SeMet supplementation $^{(21)}$.

We, therefore, conducted a 12-month, randomised, doubleblind, multi-dose, placebo-controlled intervention trial to determine the quantitative effects of supplemental SeMet on multiple biomarkers of Se status of healthy, Se-adequate adults. Our hypothesis was that the responses of such individuals could be used to impute the amount of oral Se necessary to raise plasma Se to given target concentrations. We previously presented the baseline findings from that study, comprising a complete assessment using multiple biomarkers of Se status $^{(22)}$. Here, we present the responses to supplementation including subgroup analyses examining the impact of sex and selenoprotein genotype on Se biomarkers.

\section{Subjects and methods}

This study involved healthy men and women living in the vicinity of Grand Forks, ND, who volunteered and met the eligibility criteria as described previously ${ }^{(22)}$. Volunteers resided in their homes for the duration of the year-long study; they were requested to abstain from Brazil nuts (a significant source of Se) and dietary supplements providing $\geq 50 \mu \mathrm{g}$ $\mathrm{Se} / \mathrm{d}$ for the length of the study.

Sample size was determined from simulations based on results from the NPC trial $^{(7)}$ which were used to estimate the relationship between the observed change in plasma Se after 12 months of supplementation and the effective Se dose (mcg Se/d per $\mathrm{kg}^{0.75}$ ). For each sample size modelled, 1000 sets of random numbers were generated with the following characteristics: equal numbers of men and women randomised to each of four doses of Se (0, 50, 100 and $200 \mu \mathrm{g} / \mathrm{d})$; mean body weights of the subjects in the NPC trial (women: 65 (SD 12) kg; men: 80 (SD 12) kg); predicted increase in plasma Se after 1 year of supplementation across all treatment groups of 40 (SD 10) ng/ml; a correlation structure similar to that observed in the NPC trial. These simulations indicated that, while 100 subjects would give 100\% power ( $\alpha=0.05$ ), the length of the resulting 95\% CI would exceed $20 \%$ of the predicted doses. Therefore, we set our recruitment target at a minimum of 240 subjects, which would give a CI of approximately $15 \%$ of predicted dose and accommodate $20 \%$ attrition/non-compliance. While no sex comparisons were planned, effort was made to recruit similar numbers of men and women. A flow chart showing allocation to treatment and experimental design is shown in Fig. 1.

Subjects visited the Research Center 2 weeks before and on the day of initiation of treatment, and at monthly intervals thereafter for 1 year. At each visit anthropometry was performed, a pill count-back was made and subjects received the next calendar pack of supplements. Each volunteer was given a cash honorarium pro-rated for the duration of his/her participation in the study.

This study was conducted according to the guidelines laid down in the Declaration of Helsinki. Oversight was provided by the University of North Dakota Human Subjects Committee (Grand Forks, ND, USA), which reviewed and approved the protocol. The purposes and procedures of the study were explained to the volunteers verbally and in writing, and written informed consent was obtained from each volunteer before his/her participation. The study is registered in the Clinical Trials Registry (ClinicalTrials.gov ID no. NCT00803699).

\section{Dietary supplement}

Subjects were randomly assigned to treatments consisting of a daily oral supplement containing either $0,50,100$ or $200 \mu \mathrm{g}$ Se as L-SeMet and an excipient (dicalcium phosphate) in \#2 gelatin capsules (Sabinsa Corporation, Princeton, NJ, USA). The analysed Se contents of these treatments were $0 \cdot 2,56 \cdot 0$, 101.2 and $204 \cdot 1 \mu \mathrm{g} /$ capsule, respectively. Supplement capsules were provided in numbered 31-d bubble packs at each monthly visit to the Research Center. Compliance with the study protocol was ascertained in subject interviews and by capsule count-backs. Body weight was also recorded at each of these visits so that Se dose could be adjusted for metabolic body size $\left(\mathrm{kg}^{0.75}\right)$ in the statistical analysis of the data.

\section{Dietary intake assessment}

Dietary intake was assessed at the time of randomisation to treatment and quarterly by a single self-administered FFQ patterned after the Harvard Service FFQ format ${ }^{(23)}$, as described ${ }^{(22)}$.

\section{Anthropometry}

Body weight was measured using an electronic scale. Height was measured at the beginning of the study using a wallmounted stadiometer. 


\section{Sample collection and preparation}

Blood and $24 \mathrm{~h}$ urine were collected 2 weeks before and on the day of randomisation to treatment as previously described $^{(22)}$, as well as at quarterly intervals. Blood was collected by venepuncture in duplicate $7 \mathrm{ml}$ samples into heparinised, EDTA-treated or non-treated glass tubes. Aliquots of whole blood were subjected to low-speed centrifugation to prepare erythrocyte, buffy coat, plasma and serum fractions. Urine ( $24 \mathrm{~h}$ samples) was collected in sterile polycarbonate bottles. These specimens were held at $4{ }^{\circ} \mathrm{C}$ pending the completion of screening analyses; excess portions were held at $-80^{\circ} \mathrm{C}$. Lymphocytes were prepared from whole blood after

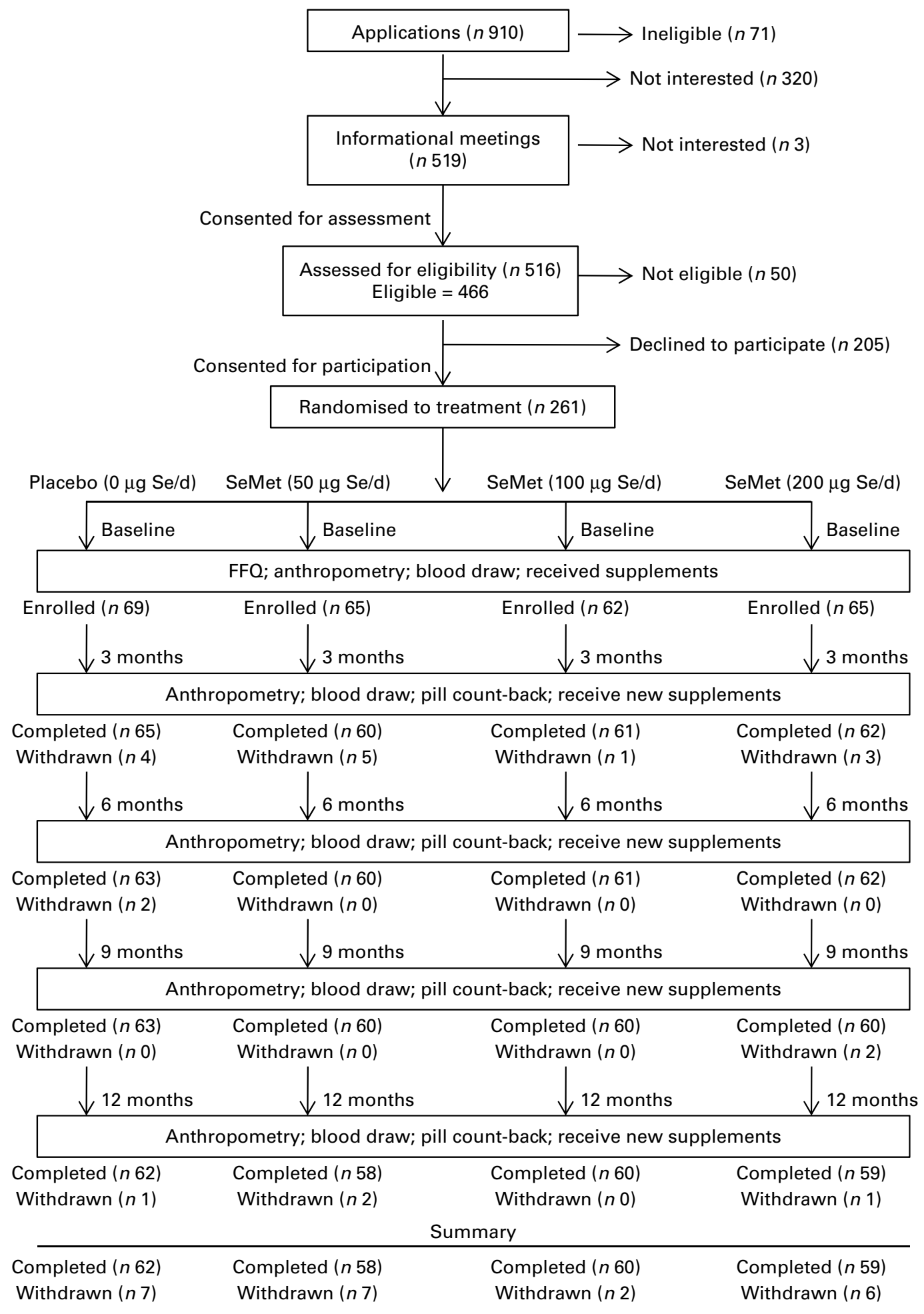

Fig. 1. Flow chart of study design and subject participation. 
lysis of erythrocytes, followed by washing, centrifugation and resuspension in $1 \%$ paraformaldehyde $\left(1 \mathrm{~h}\right.$ at $\left.2-8^{\circ} \mathrm{C}\right)$ to stabilise the cytoplasm, and final resuspension in physiologically buffered saline. Buccal cells were collected using a sterile toothbrush according to Paetau et al. ${ }^{(24)}$; cells were lysed in distilled water, and lysates were held at $-80^{\circ} \mathrm{C}$ for analysis.

\section{Analytical methods}

Biochemical analyses of methylation status and biomarkers of Se status for the cohort at baseline, before supplementation, were performed as previously described ${ }^{(22)}$. Genotyping was carried out ${ }^{(22)}$ for selenoprotein SNP: GPX1 (rs1050450) ${ }^{(25)}$, GPX4 (rs713041) ${ }^{(26)}$, SEPP1 (rs3877899 and rs7579) ${ }^{(27)}$ and SEP15 (rs5845) ${ }^{(28)}$. Se status was ascertained on the basis of the activity of GPX and the protein level of SEPP1 in serum, as well as the amounts of Se in plasma, buccal cells and urine. The activity of GPX3 (EC 1.11.1.9) was determined in plasma by the method of Lawrence \& Burk ${ }^{(29)}$. The amount of SEPP1 was measured in serum by an enzyme-linked immunoassay $^{(30)}$. Se was determined in plasma, buccal cells and urine by automated electrothermal atomic absorption spectrophotometry using a reduced palladium matrix modifier and an instrument equipped with L'Vov platforms ${ }^{(7)}$. Certified Standards were used (Alfa Aesar, Ward Hill, MA, USA; Perkin Elmer, Waltham, MA, USA and CPI, Santa Rosa, CA, USA) to prepare a calibration set daily with each batch. Calibration validation and calibration blanks were included at the beginning and end of the daily batch and at $10 \%$ frequency. Matrix effects for plasma and urine were evaluated using quantitative plasma and urine standards (NIST, Gaithersburg, MD, USA; Seronorm, Billingstad, Norway and Utak, Munich, Germany) to assess the percentage recovery of the analyte in these sample matrices. There is no commercially available quantitative standard for Se in buccal cells; therefore, matrix effects of buccal cell preparations were accounted for by performing spike recoveries using certified calibration standards added directly to one of the samples.

\section{Selenium distribution in blood}

The components of plasma Se were determined from: (1) total plasma Se; (2) measured plasma GPX3 activities; (3) measured serum SEPP1 levels. To determine the amount of GPX3derived selenocysteine from the activity of the enzyme, a rate constant of $2.8 \times 10^{4} \mathrm{nmol} / \mathrm{min}$ per $\mathrm{mg}$, molecular weight $92 \mathrm{kD}$ and a stoichiometry of $4 \mathrm{~g}$-atoms Se per mole GPX3 were assumed ${ }^{(31)}$. For selenocysteine in glycosylated SEPP1, average molecular weight $60 \mathrm{kD}$ and a stoichiometry of 9.9 g-atoms Se per mole as selenocysteine ${ }^{(32)}$ were assumed. Due to its affinity for heparin, SEPP1 was measured in serum; an inherent assumption was that insignificant quantities of SEPP1 protein precipitated from serum. The difference between the total measured Se and the amounts of Se corresponding to the activity of GPX3 and measured amount of SEPP1 was taken as the amount of Se incorporated non-specifically into plasma proteins. This is presumed to be predominately protein-bound SeMet, as only very low amounts of low molecular weight Se species appear to occur in plasma $(<1-2 \% \text { of total Se })^{(33)}$.

\section{Apoptosis and DNA damage assessment}

In order to determine whether this level of Se induced adverse apoptotic responses, that process was evaluated in lymphocytes from a random subset of sixty subjects (thirty women, thirty men) at both 0 and 12 months. Apoptosis was induced by treatment with either $\mathrm{H}_{2} \mathrm{O}_{2}(22 \mu \mathrm{M})$, cycloheximide $(9.3 \mathrm{~mm})$ or no agent $\left(180 \mathrm{~min}, 37^{\circ} \mathrm{C}\right)$ followed by permeabilisation with $70 \%$ ethanol. Cellular DNA was labelled using terminal deoxynucleotidyl transferase and bromolated deoxyuridine (BrdU) triphosphate nucleotides, after which cells were
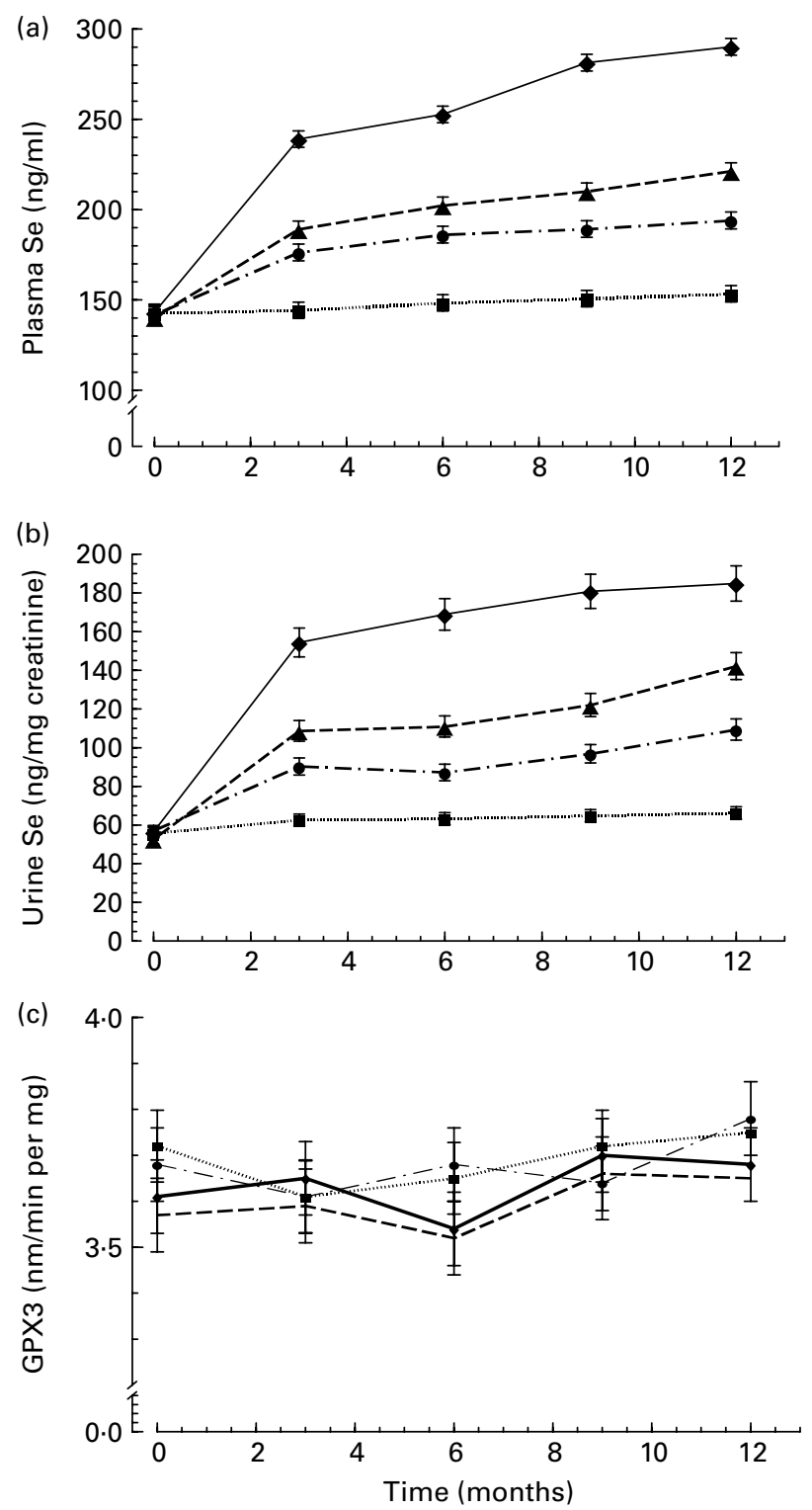

Fig. 2. Time-courses of changes in (a) plasma Se level (diet, $P<0.0001$ month, $P<0.0001$; diet $\times$ month, $P<0.0001$ ), (b) urinary Se (diet, $P<0.0001$ month, $P<0.0001$; diet $\times$ month, $P<0.0001$ ) and (c) glutathione peroxidase 3 (GPX3: diet, $P<0.75$; month, $P<0.0009$; diet $\times$ month, $P<0.34$ ) activity in response to L-selenomethionine supplementation. Values are means, with their standard errors represented by vertical bars. 
probed in the dark with fluorescein $\sim$ BrdU mAb (APO$\mathrm{BrdU}^{\mathrm{TM}}$; Phoenix Flow Systems, Inc., San Diego, CA, USA, catalogue no. AU1001). DNA was stained using propidium iodide (PI)/RNase $\mathrm{A}$ and within $2 \mathrm{~h}$ samples were analysed by flow cytometry using a four-colour instrument (Epics-XL, Beckman-Coulter, Miami, FL, USA) equipped with a $488 \mathrm{~nm}$ laser. BrdU and PI were detected by absorbance at 525 and $620 \mathrm{~nm}$, respectively. BrdU incorporation was plotted $v$. PI incorporation with a logical gate excluding doublets. A total of 15000 events were collected (flow rate 200-600 events/s) in the region encompassing the main population of intact single leucocytes. Data were analysed using Summit ${ }^{\mathrm{TM}}$ Offline flow cytometry analysis software (Cytomation, Inc., Fort Collins, CO, USA).

The extent of DNA damage in peripheral blood lymphocytes was measured by the alkaline comet assay as described

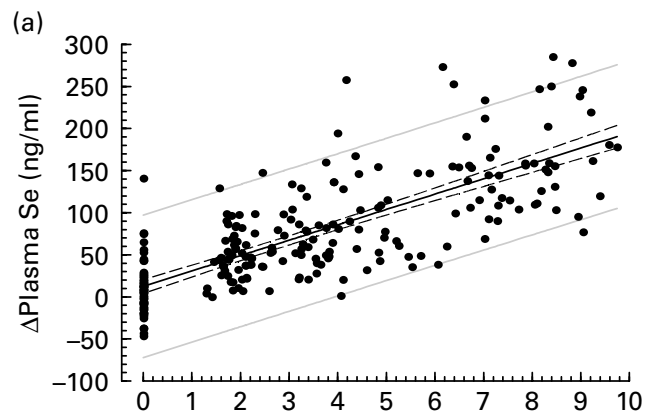

(b)

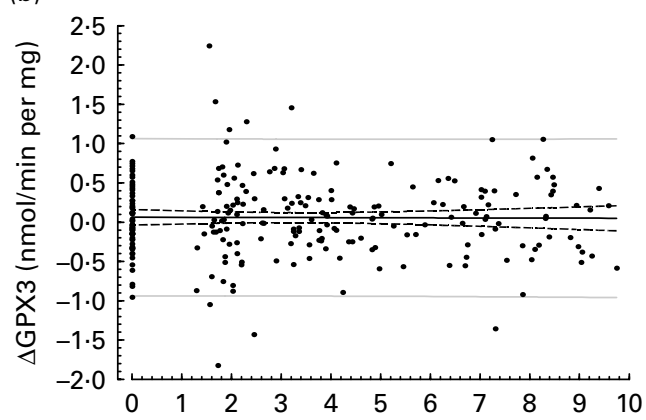

(c)

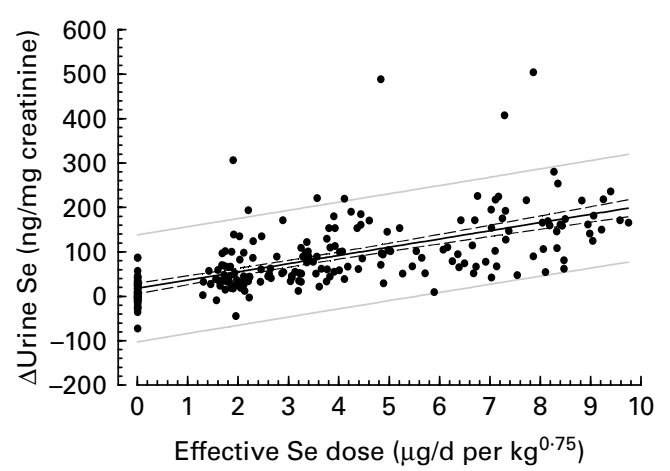

by Waters et $a l .{ }^{(34)}$. The extent of DNA damage was assessed under basal conditions and after ex vivo exposure of lymphocytes to $22 \mu \mathrm{M}-\mathrm{H}_{2} \mathrm{O}_{2}$. Damage was scored in 200 cells randomly selected from each sample by a single examiner blinded to treatment. SYBR Green 1 stained nucleoids were examined at $200 \times$ magnification using an epifluorescence microscope. Each cell was scored visually by the method of Duthie \& Collins ${ }^{(35)}$ : no damage (type 0 ); mild to moderate damage (types 1 and 2) and extensive DNA damage (types 3 and 4). Extent of damage was expressed as the percentage of cells of types 3 and 4 .

\section{Statistical analyses}

All statistical analyses were performed using SAS version 9.1.3 (SAS Institute, Inc., Cary, NC, USA). Data for buccal Se, urine
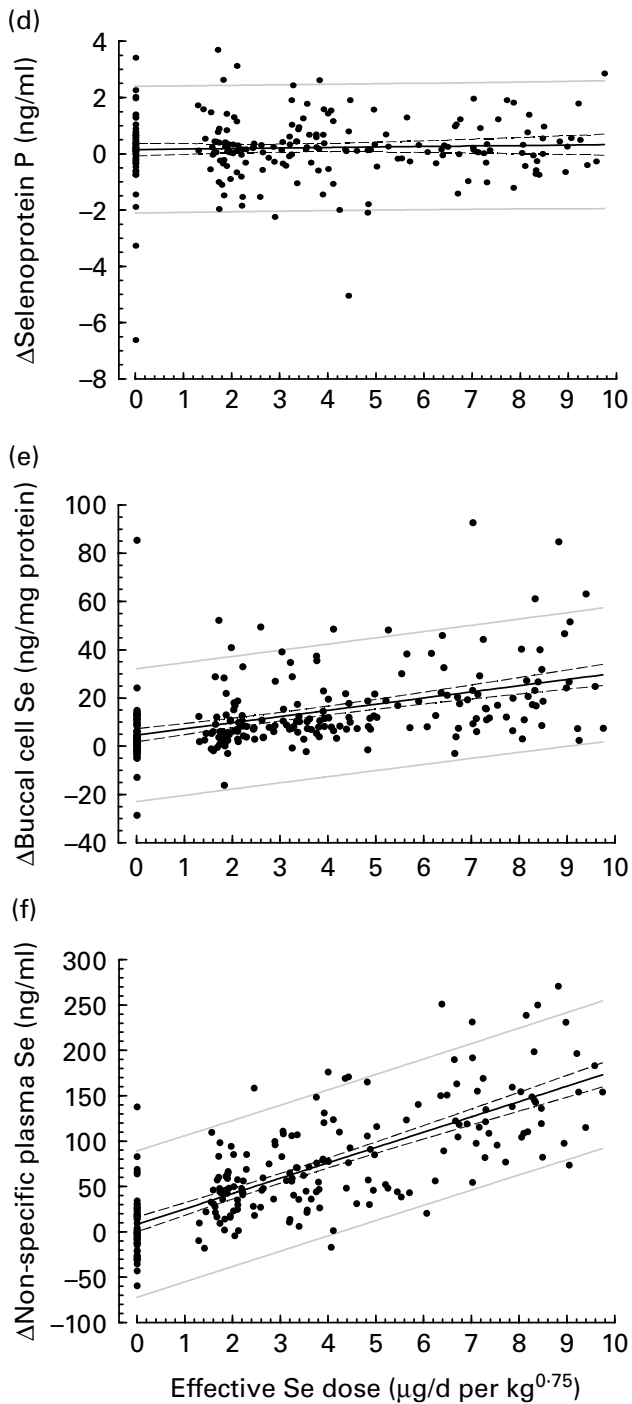

Fig. 3. Relationships of 1-year changes in (a) plasma Se ( $\Delta$ plasma Se $=12.6+18.2$ (effective dose); $R^{2}=0.60, P=0.0001$ ), (b) glutathione peroxidase 3 (GPX3) activity ( $\Delta$ plasma GPX $=0.06-0.001$ (effective dose); $R^{2}=0.00001, P=0.91$ ), (c) urinary Se $\left(\Delta\right.$ urine Se $=17.4+18.6$ (effective dose); $R^{2}=0.44$, $P=0.0001)$, (d) selenoprotein P (SEPP1; $\Delta$ SEPP1 $=0.15+0.018$ (effective dose); $\left.R^{2}=0.002, P=0.51\right)$, (e) buccal cell Se $(\Delta$ buccal cell Se $=4.6+2 \cdot 6($ effective dose); $\left.R^{2}=0.22, P=0.0001\right)$ and (f) non-specific plasma Se ( $\Delta$ non-specific plasma Se $=8.4+16.9$ (effective dose); $\left.R^{2}=0.58, P=0.0001\right)$ with effective

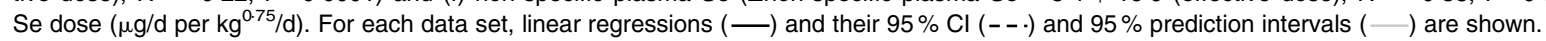


Se, SEPP1, folate, homocysteine (Hcy), vitamin $\mathrm{B}_{12}$ and thyroid-stimulating hormone were highly skewed for which reason they were logarithmically transformed so that their distributions would more closely approximate normal. For these variables, geometric means with the $\pm 1 \mathrm{sD}$ confidence limits are reported; other data are expressed as arithmetic means and standard deviations. Nucleic acid data were extracted using Robust Multi-Array Average (RMA) in mAdb (a MultiArray database tool) (National Cancer Institute, National Institutes of Health) and analysed by paired $t$ tests $(P<0.05)$, adjusting for multiplicity using the false discovery rate test.

Repeated-measures ANOVA was used to test for effects of supplemental Se level over time. When appropriate, Tukey's contrasts were used to compare the supplement levels at each individual time point. Regression analysis was used to model the change in Se status given the effective Se dose, calculated as the Se dose consumed (adjusted for reported compliance) per metabolic body size defined as $\mathrm{kg}^{0.75}$. Categorical variables were included in the regressions to test for effects of sex or genotype.

\section{Results}

A total of 261 subjects (106 men, 155 women) were enrolled in the study and randomised to the treatments. Of these, 243 subjects completed the 12-month study, for an attrition rate of $7 \%$. Of the dropouts (eight men, ten women), none complained of side-effects. Compliance with the treatment protocol, as ascertained by monthly capsule count-backs for subjects completing the study, was $97 \%$.

The study subjects were genotyped ${ }^{(22)}$ for selenoprotein SNPs that have been correlated with cancer incidence or mechanistically implicated in carcinogenesis ${ }^{(23-26)}$, and exhibited the following genotype frequencies. The prevalence of dominant alleles in this population was: GPX1 (Pro198Leu; rs1050450: $46 \% \mathrm{C} / \mathrm{C}, 43 \% \mathrm{~T} / \mathrm{C}, 11 \% \mathrm{~T} / \mathrm{T})$, GPX4 (3'-UTR (untranslated region); rs713041: $28 \% \mathrm{C} / \mathrm{C}, 52 \% \mathrm{~T} / \mathrm{C}, 20 \% \mathrm{~T} /$ T), SEPP1 (Ala234Thr; rs3877899: 58\% G/G, 38\% A/G, 4\% A/A and 3'-UTR; rs7579: $44 \% \mathrm{G} / \mathrm{G}, 44 \% \mathrm{~A} / \mathrm{G}, 12 \% \mathrm{~A} / \mathrm{A})$ and SEP15 (3'-UTR; rs5845: 65\% C/C, $31 \% \mathrm{~T} / \mathrm{C}, 4 \% \mathrm{~T} / \mathrm{T}$ ).

This cohort was of relatively high Se status, as indicated by the baseline values of the biomarkers of Se status, e.g. plasma Se level $(142.0(\mathrm{SD} 23.5) \mathrm{ng} / \mathrm{ml})$ and an estimated average Se intake of 109 (SD 44) $\mu \mathrm{g} / \mathrm{d}^{(22)}$. We found no evidence that the background intake of Se from dietary sources, as estimated by a quarterly FFQ, differed significantly between treatment groups or changed significantly during the course of the study. In consideration of the analysed Se contents of the supplements, these treatments provided estimated total Se intakes of approximately 109, 165, 210 and $313 \mu \mathrm{g} / \mathrm{d}$. Thus, all of the subjects were consuming Se at levels greater than the recommended daily allowance, which was set on the basis of maximal expression of GPX3. There is no recommendation for the concentration of Se in plasma.
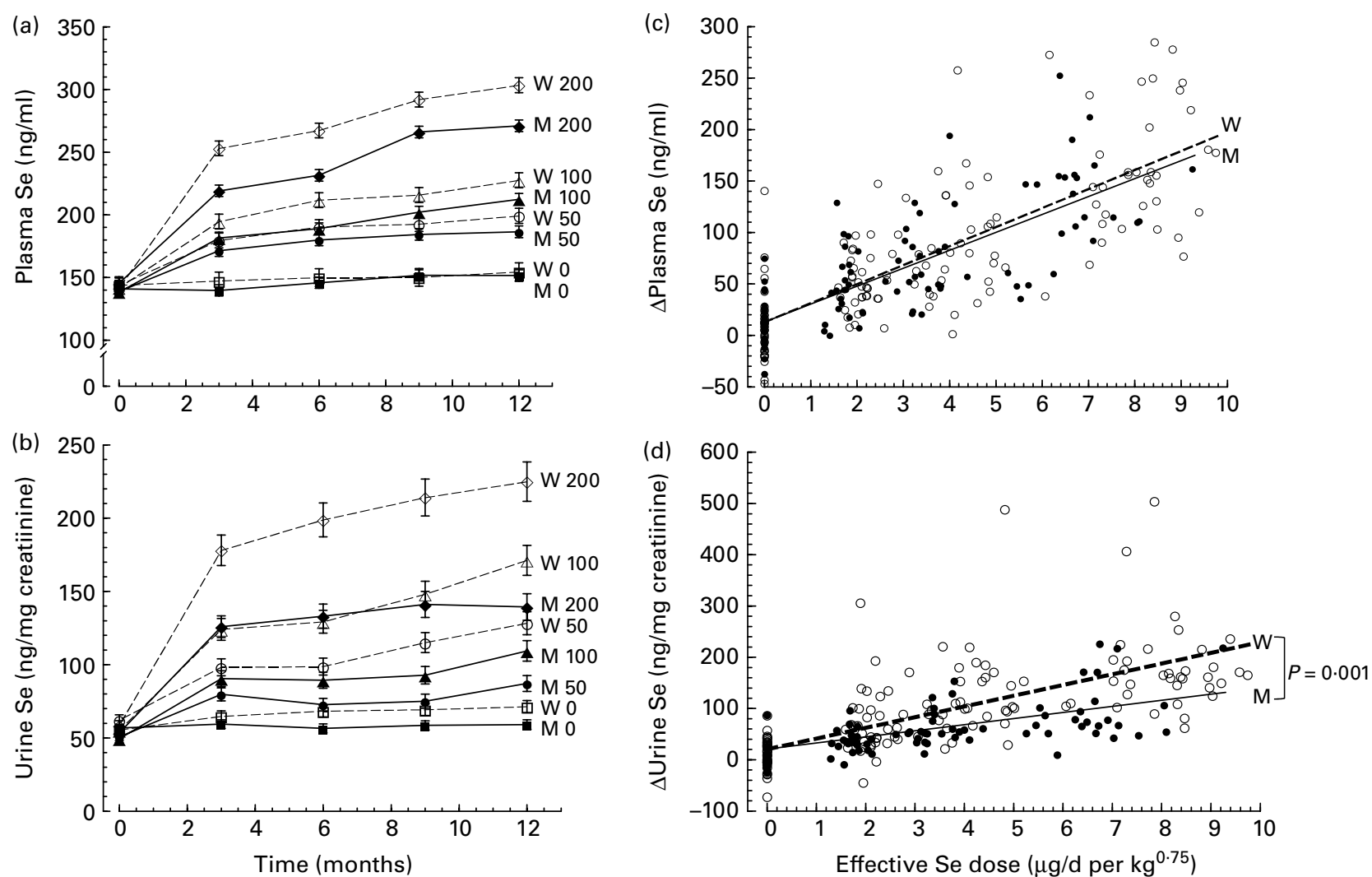

Fig. 4. Relationships of responses of $(a, c)$ plasma and (b, d) urinary Se levels to selenomethionine supplementation for men (M) and women (W): (a, b) doseresponses over time and $(c, d) 1$-year dose-responses to effective Se dose $\left(\mu \mathrm{g} / \mathrm{d} \mathrm{per} \mathrm{kg}^{0.75}\right)$. For each data set, the linear regression is shown for each sex. (d) M: $\Delta$ urine $\mathrm{Se}=20 \cdot 4+12 \cdot 0$ (effective dose) and W: $\Delta$ urine $\mathrm{Se}=20 \cdot 4+20 \cdot 9$ (effective dose). 
Supplementation with SeMet produced significant increases in some but not all biomarkers of Se status. Dose-dependent increases in the Se contents of plasma (Fig. 2(a)) and urine (Fig. 1(b)) manifested within 3 months, with apparent plateaus being reached by 9-12 months. No significant treatment effect on GPX3 activity was detected, although that parameter showed a small $(<2 \%)$ but significant increase over the course of the study (Fig. 2(c)).

The 1-year changes in the levels of Se in plasma, urine and buccal cells, and in the non-specific component of plasma Se, each showed significant linear relationships with effective Se dose $\left(\mu \mathrm{g} / \mathrm{d}\right.$ per $\mathrm{kg}^{0.75}$ ) (Fig. 3). No changes were observed for GPX3 activity or SEPP1 level. The dose-dependent increase in urinary Se excretion of women was $74 \%$ greater $(P=0 \cdot 001)$ than that of men (Fig. 4), and for individuals of both sexes with the GPX1 T/T genotype was $59 \%$ greater $(P<0.006)$ than those with the GPX1 C/C genotype (Fig. 5). These differences were significant within 3 months of SeMet supplementation. Individuals with GPX1 T/T genotype also had significantly lower $(7 \%, P<0.05)$ plasma Se levels than those with the GPX1 C/C genotype at baseline ${ }^{(22)}$. No other differences in responses to SeMet-supplementation were associated with the selenoprotein genotypes tested.

The major components of plasma Se were estimated from the difference between total plasma Se and the measured activities and amounts, respectively, of GPX3 and SEPP1, as described previously ${ }^{(22)}$. By these estimates, the increase in plasma Se produced by SeMet-supplementation was limited to the non-specific component of that compartment (Table 1).

SeMet-supplementation produced no significant effects on spontaneous or induced apoptosis of peripheral lymphocytes (Table 1). Similarly, no significant difference in spontaneous or induced lymphocyte DNA damage was detected in the alkaline comet assay (Table 1). No significant effects of SeMetsupplementation were detected on the levels of folate, vitamin $\mathrm{B}_{12}$, Hcy, thyroid hormones or buffy coat $\mathrm{HbA}_{1 \mathrm{c}}$ (Table 1 ).

\section{Discussion}

The baseline plasma Se level of this cohort, $142 \cdot 0$ (SD 23.5) ng/ $\mathrm{ml}$, shows that this population was adequately nourished with respect to Se prior to supplementation. Nevertheless, plasma Se increased with SeMet-supplementation, reaching a new steady state within 9-12 months. That change, from the initial steady state to the other, after a year of SeMet-supplementation was described by the following relation:

$$
\begin{aligned}
& \Delta \mathrm{Se}_{\mathrm{pl}}(\mathrm{ng} / \mathrm{ml})=12.6 \mathrm{ng} / \mathrm{ml}+18.2 \mathrm{ng} \mathrm{d} \mathrm{kg}{ }^{0.75} / \mathrm{ml} \text { per } \mu \mathrm{g} \\
& \times \operatorname{Se}_{\text {in }}(P<0.0001),
\end{aligned}
$$

where $\Delta$ Se is steady-state change in plasma Se concentration; and $\mathrm{Se}_{\text {in }}$ is regular Se intake as SeMet expressed as $\mu \mathrm{g} / \mathrm{d}$ per $\mathrm{kg}^{0.75}$

That the $y$-intercept is significantly different from 0 $(P<0.003)$ reflects an $8.9 \%$ increase in mean plasma se level of the non-supplemented members of the cohort during the course of the study. Apart from this apparently secular effect, the amount of increased intake of Se (as SeMet) required to raise plasma Se concentration to a particular target level ( $\left.\mathrm{Se}_{\mathrm{pl}-\text { target }}\right)$ is:

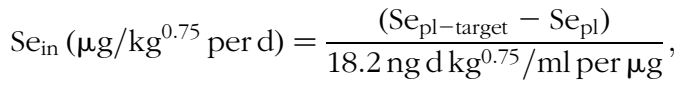

where $\mathrm{Se}_{\mathrm{pl}}$ is current plasma Se concentration, $\mathrm{ng} / \mathrm{ml}$; and $\mathrm{Se}_{\mathrm{pl} \text {-target }}$ is target plasma Se concentration, $\mathrm{ng} / \mathrm{ml}$.

The increase in plasma Se in this cohort did not involve increases in the specific selenoproteins in plasma (GPX3, SEPP1), indicating that the baseline Se intake, estimated to be 109.1 (SD 43.6) $\mu \mathrm{g} / \mathrm{d}^{(22)}$, was sufficient to support maximal expression of each. Instead, the response of plasma Se was explained by changes solely in the non-specific component of plasma Se, which comprised $46 \%$ of plasma Se at baseline and increased, over 1 year of SeMet supplementation, to $46 \cdot 6$, $56 \cdot 3,61.8$ and $70.5 \%$ of plasma total Se with 0, 50, 100 and $200 \mu \mathrm{g} \mathrm{Se} / \mathrm{d}$, respectively. That increase is described by the following relation:

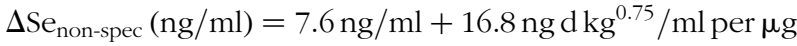

$$
\begin{aligned}
& \times \operatorname{Se}_{\text {intake }}(P<0.0001),
\end{aligned}
$$

where $\Delta \mathrm{Se}_{\text {non-spec }}$ is the steady-state change in non-specific plasma Se level; and $\mathrm{Se}_{\mathrm{in}}$ is regular $\mathrm{Se}$ intake as SeMet
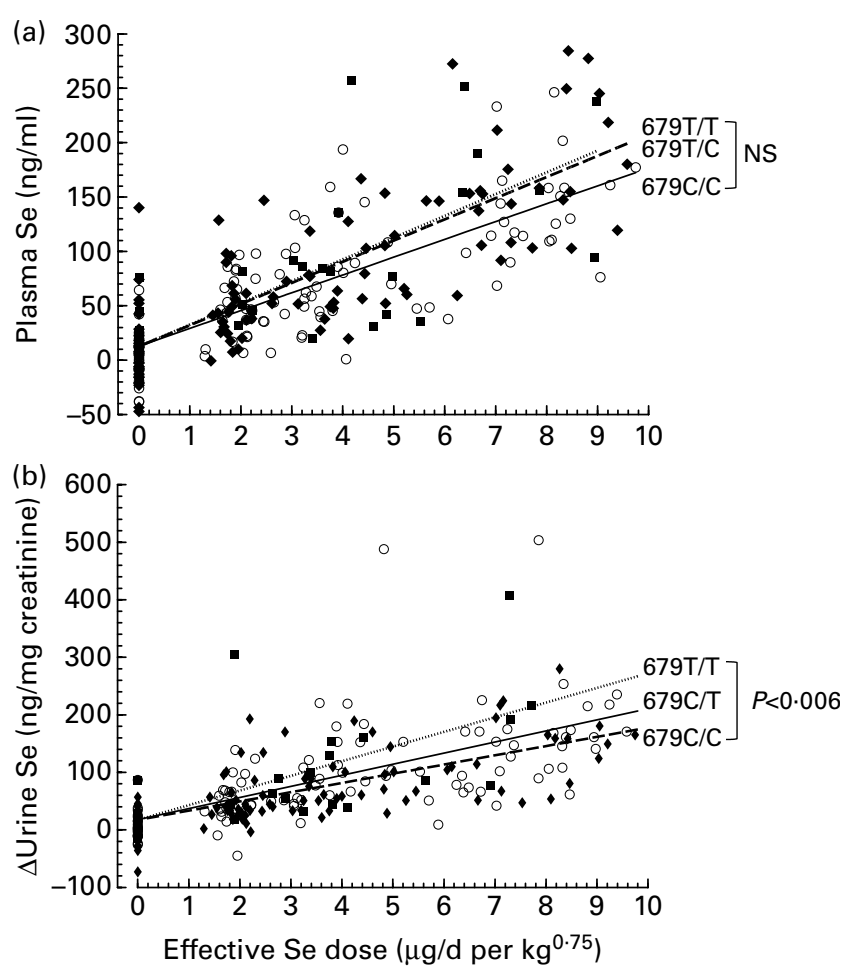

Fig. 5. Relationships of 1-year changes in urinary Se levels of subjects of different glutathione peroxidase (GPX1) genotypes and effective Se dose $\left(\mu \mathrm{g} / \mathrm{d}\right.$ per kg ${ }^{0.75}$ ); $\mathbf{0}:$ GPX1 679 T/T (Leu198Leu); •: GPX1 679 T/C (Leu198Pro); : GPX1 $679 \mathrm{C} / \mathrm{C}$ (Pro198Pro). For each data set, the linear regression is shown. (a) GPX1 $679 \mathrm{~T} / \mathrm{T}$ : $\Delta$ plasma $\mathrm{Se}=12 \cdot 8+20.0$ (effective dose); GPX1 679 T/C: $\Delta$ plasma Se $=12.8+16.4$ (effective dose); GPX1 $679 \mathrm{C} / \mathrm{C}$ : $\Delta$ plasma $\mathrm{Se}=12 \cdot 8+19.5$ (effective dose). (b) GPX1 $679 \mathrm{~T} / \mathrm{T}: \Delta$ urine $\mathrm{Se}=17 \cdot 3+25.4$ (effective dose); GPX1 679 T/C: $\Delta$ urine Se $=17 \cdot 3+19 \cdot 3$ (effective dose); GPX1 679 C/C: $\Delta$ urine $\mathrm{Se}=17 \cdot 3+16 \cdot 0$ (effective dose). 
Table 1. Summary of responses to selenium supplementation

(Mean values and standard deviations)

\begin{tabular}{|c|c|c|c|c|c|c|c|c|c|c|c|c|c|c|c|}
\hline \multirow[b]{4}{*}{ Characteristics } & \multirow{2}{*}{\multicolumn{5}{|c|}{ Baseline values ${ }^{*}$}} & \multicolumn{10}{|c|}{ 12-month values*, by Se dose $(\mu \mathrm{g} / \mathrm{d})$} \\
\hline & & & & & & \multicolumn{5}{|c|}{0} & \multicolumn{5}{|c|}{50} \\
\hline & \multicolumn{5}{|c|}{ Geometric } & \multicolumn{5}{|c|}{ Geometric } & \multicolumn{5}{|c|}{ Geometric } \\
\hline & Mean & SD & mean & $-1 \mathrm{sD}$ & $1 \mathrm{sD}$ & Mean & SD & mean & $-1 \mathrm{sD}$ & $1 \mathrm{sD}$ & Mean & SD & mean & $-1 \mathrm{SD}$ & $1 \mathrm{SD}$ \\
\hline \multicolumn{16}{|l|}{ Anthropometry } \\
\hline Age (years) & 49.6 & $16 \cdot 3$ & & & & & & & & & & & & & \\
\hline $\mathrm{BMI}\left(\mathrm{kg} / \mathrm{m}^{2}\right)$ & $27 \cdot 4$ & 5.0 & & & & $27 \cdot 0$ & 4.7 & & & & $27 \cdot 1$ & 4.3 & & & \\
\hline Metabolic body size $\left(\mathrm{kg}^{0.75}\right)$ & $26 \cdot 3$ & 4.3 & & & & $26 \cdot 0$ & 4.0 & & & & $25 \cdot 9$ & $4 \cdot 2$ & & & \\
\hline \multicolumn{16}{|l|}{ Biomarkers of Se status } \\
\hline Plasma Se (ng/ml) & $142 \cdot 0$ & 23.5 & & & & $153 \cdot 4^{\mathrm{d}}$ & $26 \cdot 6$ & & & & $194.8^{\mathrm{c}}$ & 38.6 & & & \\
\hline Plasma GPX3 (nm/min per mg) & 3.64 & 0.54 & & & & 3.75 & 0.53 & & & & 3.77 & 0.70 & & & \\
\hline Plasma SEPP1 ( $\mu \mathrm{g} / \mathrm{ml})$ & & & 3.43 & 2.61 & 4.51 & & & 3.61 & 2.90 & 4.50 & & & 3.69 & 2.79 & 4.87 \\
\hline Non-specific plasma Se† $(\mathrm{ng} / \mathrm{ml})$ & 68.5 & $27 \cdot 1$ & & & & $73.5^{\mathrm{c}}$ & 29.1 & & & & $112 \cdot 3^{b}$ & 38.2 & & & \\
\hline Buccal cell Se (ng/mg protein) & & & 8.39 & 5.59 & 12.59 & & & $11.51^{\mathrm{C}}$ & 6.77 & 19.55 & & & $16 \cdot 15^{\mathrm{b}}$ & $10 \cdot 23$ & 25.49 \\
\hline Urine $\mathrm{Se}(\mathrm{ng} / \mathrm{mg}$ creatinine) & & & $55 \cdot 3$ & $41 \cdot 1$ & $74 \cdot 3$ & & & $65 \cdot 6^{\mathrm{d}}$ & 47.8 & $90 \cdot 0$ & & & $110 \cdot 6^{c}$ & 72.7 & $168 \cdot 2$ \\
\hline Urine $8 \mathrm{OHdG}$ & & & $10 \cdot 8$ & $5 \cdot 3$ & $22 \cdot 2$ & & & 11.8 & 5.4 & $25 \cdot 1$ & & & 13.5 & $5 \cdot 2$ & 34.8 \\
\hline \multicolumn{16}{|l|}{ Other metabolic markers } \\
\hline Plasma folate $(\mu \mathrm{g} / \mathrm{ml})$ & & & $25 \cdot 1$ & $13 \cdot 2$ & 47.8 & & & 20.6 & $13 \cdot 3$ & $32 \cdot 0$ & & & 23.4 & 13.6 & $40 \cdot 0$ \\
\hline Plasma vitamin $B_{12}(\mathrm{pg} / \mathrm{ml})$ & & & 496 & 313 & 786 & & & 495 & 288 & 849 & & & 457 & 288 & 726 \\
\hline Plasma Hcy $(\mu \mathrm{g} / \mathrm{ml})$ & & & 6.8 & $5 \cdot 2$ & 8.9 & & & $6 \cdot 3$ & 4.5 & 8.8 & & & $6 \cdot 1$ & 4.5 & 8.3 \\
\hline $\mathrm{TSH}(\mathrm{mU} / \mathrm{l})$ & & & 2.35 & $1 \cdot 21$ & 4.56 & & & $2 \cdot 14$ & 1.02 & 4.49 & & & $2 \cdot 36$ & 1.08 & $5 \cdot 16$ \\
\hline Free $T_{3}$ & 2.91 & 0.59 & & & & 3.01 & 0.64 & & & & 2.94 & 0.63 & & & \\
\hline Free $\mathrm{T}_{4}$ & 1.35 & 0.18 & & & & 1.35 & 0.17 & & & & 1.39 & 0.19 & & & \\
\hline Glucose & 89.9 & $13 \cdot 1$ & & & & & & & & & & & & & \\
\hline $\mathrm{HbA}_{1 \mathrm{c}}$ & 4.8 & 0.7 & & & & 4.7 & 0.8 & & & & 4.7 & 0.6 & & & \\
\hline \multicolumn{16}{|l|}{ Apoptosis datał } \\
\hline Spontaneous & & & 1.72 & 1.01 & 2.92 & & & 1.82 & $1 \cdot 14$ & 2.92 & & & 1.77 & 0.95 & 3.29 \\
\hline $\mathrm{H}_{2} \mathrm{O}_{2}$-induced & & & 3.94 & $2 \cdot 18$ & $7 \cdot 10$ & & & 4.01 & $2 \cdot 23$ & $7 \cdot 24$ & & & 3.71 & 2.08 & 6.62 \\
\hline $\mathrm{CHX}$-induced & & & $6 \cdot 23$ & 2.53 & $15 \cdot 33$ & & & 6.96 & $2 \cdot 80$ & $17 \cdot 29$ & & & $7 \cdot 17$ & 3.46 & 14.88 \\
\hline \multicolumn{16}{|l|}{ DNA damage, alkaline comet assay } \\
\hline Basal (\% severe damage)§ & & & 4.70 & 0.82 & 11.52 & & & 14.23 & 3.07 & 31.64 & & & 9.09 & 0.15 & 36.72 \\
\hline $\mathrm{H}_{2} \mathrm{O}_{2}$-treated (\% severe damage) $\S$ & & & 29.91 & 18.98 & $42 \cdot 15$ & & & 38.07 & 19.25 & 58.97 & & & 37.51 & 9.57 & $71 \cdot 16$ \\
\hline
\end{tabular}


Table 1. Continued

\begin{tabular}{|c|c|c|c|c|c|c|c|c|c|c|}
\hline \multirow[b]{3}{*}{ Characteristics } & \multicolumn{10}{|c|}{ 12-month values ${ }^{*}$, by Se dose $(\mu \mathrm{g} / \mathrm{d})$} \\
\hline & \multicolumn{5}{|c|}{100} & \multicolumn{5}{|c|}{200} \\
\hline & Mean & SD & $\begin{array}{c}\text { Geometric } \\
\text { mean }\end{array}$ & $-1 \mathrm{SD}$ & $1 \mathrm{sD}$ & Mean & SD & $\begin{array}{c}\text { Geometric } \\
\text { mean }\end{array}$ & $-1 \mathrm{SD}$ & $1 \mathrm{sD}$ \\
\hline \multicolumn{11}{|l|}{ Anthropometry } \\
\hline \multicolumn{11}{|l|}{ Age (years) } \\
\hline $\mathrm{BMI}\left(\mathrm{kg} / \mathrm{m}^{2}\right)$ & 27.2 & 5.3 & & & & 27.8 & 5.4 & & & \\
\hline Metabolic body size $\left(\mathrm{kg}^{0.75}\right)$ & $26 \cdot 2$ & 4.6 & & & & $26 \cdot 7$ & 4.5 & & & \\
\hline \multicolumn{11}{|l|}{ Biomarkers of Se status } \\
\hline Plasma Se (ng/ml) & $221 \cdot 1^{\mathrm{b}}$ & 49.4 & & & & $291 \cdot 6^{a}$ & 59.8 & & & \\
\hline Plasma GPX3 $(\mathrm{nm} / \mathrm{min}$ per $\mathrm{mg})$ & 3.64 & 0.59 & & & & 3.68 & 0.55 & & & \\
\hline Plasma SEPP1 $(\mu \mathrm{g} / \mathrm{ml})$ & & & 3.70 & 2.92 & 4.68 & & & 3.73 & 2.97 & 4.69 \\
\hline Non-specific plasma Se† $(\mathrm{ng} / \mathrm{ml})$ & $137 \cdot 1^{\mathrm{b}}$ & 41.6 & & & & $202 \cdot 7^{\mathrm{a}}$ & $51 \cdot 1$ & & & \\
\hline Buccal cell Se (ng/mg protein) & & & $20.59^{\mathrm{b}}$ & 13.63 & 31.09 & & & $30 \cdot 23^{\mathrm{a}}$ & 17.78 & 51.41 \\
\hline Urine Se (ng/mg creatinine) & & & $140 \cdot 0^{\mathrm{b}}$ & 91.6 & 213.5 & & & $187 \cdot 8^{\mathrm{a}}$ & $122 \cdot 9$ & 286.9 \\
\hline Urine $80 \mathrm{HdG}$ & & & 13.9 & 5.8 & 33.0 & & & 14.3 & 5.6 & 36.8 \\
\hline \multicolumn{11}{|l|}{ Other metabolic markers } \\
\hline Plasma folate $(\mu \mathrm{g} / \mathrm{ml})$ & & & 23.5 & 13.7 & 40.4 & & & 21.8 & $12 \cdot 6$ & 37.9 \\
\hline Plasma vitamin $B_{12}(\mathrm{pg} / \mathrm{ml})$ & & & 461 & 309 & 687 & & & 447 & 288 & 693 \\
\hline Plasma Hcy $(\mu \mathrm{g} / \mathrm{ml})$ & & & 6.0 & 4.4 & 8.1 & & & 6.0 & 4.4 & 8.1 \\
\hline $\mathrm{TSH}(\mathrm{mU} / \mathrm{l})$ & & & 2.61 & 1.46 & 4.65 & & & 2.66 & 1.31 & 5.41 \\
\hline Free $\mathrm{T}_{3}$ & 2.92 & 0.56 & & & & 3.04 & 0.51 & & & \\
\hline Free $T_{4}$ & 1.39 & 0.22 & & & & 1.35 & 0.18 & & & \\
\hline Glucose & & & & & & & & & & \\
\hline $\mathrm{HbA}_{1 \mathrm{c}}$ & 4.9 & 0.8 & & & & 4.7 & 0.6 & & & \\
\hline \multicolumn{11}{|l|}{ Apoptosis datał } \\
\hline Spontaneous & & & 1.77 & 0.98 & 3.19 & & & 1.68 & 0.96 & 2.94 \\
\hline $\mathrm{H}_{2} \mathrm{O}_{2}$-induced & & & 3.60 & 1.93 & 6.69 & & & 3.22 & 1.95 & $5 \cdot 31$ \\
\hline $\mathrm{CHX}$-induced & & & 7.54 & 3.13 & $18 \cdot 17$ & & & 9.12 & 3.10 & 26.84 \\
\hline \multicolumn{11}{|l|}{ DNA damage, alkaline comet assay } \\
\hline Basal (\% severe damage)§ & & & 14.55 & 0.03 & 51.39 & & & $5 \cdot 32$ & 0.73 & 13.73 \\
\hline $\mathrm{H}_{2} \mathrm{O}_{2}$-treated (\% severe damage) $\S$ & & & 39.70 & $7 \cdot 31$ & 78.58 & & & 34.84 & 21.69 & 49.28 \\
\hline
\end{tabular}


expressed as $\mu \mathrm{g} \mathrm{Se} / \mathrm{d}_{\text {per }} \mathrm{kg}^{0.75}$ ( $y$-intercept is not significantly different from $0(P<0 \cdot 08))$

Sexually dimorphic aspects of Se status and response to supplementation have recently been reviewed by Schomburg \& Schweizer ${ }^{(36)}$. Previously, Méplan et al. ${ }^{(37)}$ observed that response of the predominate plasma selenoprotein, SEPP1, to Se supplementation differed by sex. The same group noted that the effect of SNP on the expression of selenoprotein GPX4 depended on sex ${ }^{(38)}$. Our present study results show that SeMet-supplementation increased urinary Se output more in women than men, suggesting significant, sex-specific differences in Se metabolism. In rodents, it has been shown that selenoprotein biosynthesis is sexually dimorphic in the liver and kidney ${ }^{(39,40)}$ even though total Se concentrations and SEPP levels in serum do not differ. Accordingly, Se supplementation in mice affected selenoprotein biosynthesis in a sex-specific manner, indicating that hepatic metabolism of dietary Se differs in males and females ${ }^{(41)}$. It is possible that such an effect may underlie the sexual dimorphic urinary Se excretion that we observed in this study involving human subjects.

We also found increased urinary Se output in individuals with the GPX1 T/T relative to those of the GPX1 C/C genotype. Differential turnover of the GPX1 enzyme, which accounts for some $60 \%$ of liver $\mathrm{Se}^{(42)}$, is likely to affect whole-body Se balance; this may explain the increased urinary output. It is also possible that the urinary response related to the fact that individuals with GPX1 T/T have significantly lower (7\%) baseline plasma Se levels than individuals with GPX1 C/C ${ }^{(22)}$. Cominetti et al. ${ }^{(43)}$ observed a similar difference for morbidly obese women of lower Se status in response to Se from Brazil nuts; however, in their relatively small ( $n$ 37) study, they were unable to detect the significant genotyperelated differences in baseline plasma Se which we observed in the present cohort ${ }^{(22)}$. Hu \& Diamond ${ }^{(25)}$ found that the GPX1 activity response of cultured breast cancer cells ectopically expressing the GPX1 T/T genotype was less than that of cells expressing the GPX1 C/C genotype. That this difference may be related to cancer risk is suggested by the findings of GPX1 genotype as a determinant of the risk of lung cancer among male smokers in the Finnish Alpha-Tocopherol BetaCarotene (ATBC) Trial $^{(44)}$ and breast cancer in American women $^{(23,45)}$, as well as the loss of heterozygosity in lung tumours ${ }^{(46)}$.

Gonzalez et al. $^{(47)}$ found serum Se and Hcy concentrations to vary inversely, explaining $5.8 \%$ of the variance of the latter $(2 \cdot 2 \%$ of the variance was accounted for by serum folate concentration). Finding a $63 \%$ reduction $(P=0.013)$ in the risk of elevated Hcy concentrations for subjects with serum Se levels in the highest tertile, they concluded that Se should be considered as a potential factor for lowering serum Hcy. The present study, however, detected no effects of SeMet supplementation on circulating levels of folate, vitamin $\mathrm{B}_{12}$ or Hcy.

While Se is required for each of the deiodinases involved in thyroid hormone metabolism, that Se supplementation did not affect thyroid hormone levels suggests that those selenoproteins were maximally expressed in these subjects before supplementation. These findings are consistent with our previous results with another cohort of Se-adequate adults ${ }^{(15)}$, although another group ${ }^{(48,49)}$ reported such changes.

These results provide no evidence of adverse effects of this level of SeMet supplementation. No effects on lymphocyte DNA damage were observed, although DNA damage was reported for morbidly obese women with the GPX1 679 T/T genotype ${ }^{(43)}$ and have been observed in animal models in response to selenite ${ }^{(50)}$. Neither did SeMet affect spontaneous or peroxide-induced apoptosis of peripheral lymphocytes.

A limitation of the present study was the use of SeMet as the intervention agent. The biological utilisation of this form of Se is known to be affected by dietary Met ${ }^{(51-53)}$, due to the competition of Met and SeMet ${ }^{(53)}$ for incorporation into general proteins. This cohort was adequately nourished with respect to total protein, and thus Met. Therefore, Se-enriched yeast, which is mostly SeMet, would be expected to have given comparable results. However, supplementation with inorganic Se, which does not contribute to the non-specific fraction of plasma se as defined in this study, would be expected to have increased primarily urinary Se and, perhaps, its precursors in the non-protein bound fraction of plasma ${ }^{(33)}$.

\section{Conclusions}

The present study demonstrates the feasibility of tracking responses to SeMet supplementation in a cohort that is not deficient in the nutrient. In such a cohort, biomarkers with clear functional significance that are limited by Se deficiency, such as GPX3 activity and SEPP1 level, are already maximally expressed. Therefore, they are of no utility as indicators of further increases in Se status. Such tracking demands the use of biomarkers related to tissue/body Se pools. We have demonstrated the use of four such biomarkers: plasma total Se, plasma non-specific Se, buccal cell Se and urinary Se. Each responded to SeMet supplementation; those responses were linear with effective Se dose (i.e. corrected for body mass) over the period of time under investigation. The non-specific component of plasma Se, which we imputed from direct measurements of total plasma Se, SEPP1 and GPX3 activity, was responsive to SeMet supplementation, reflecting the incorporation of SeMet into plasma proteins.

Because SeMet is the dominant form of Se in foods ${ }^{(54,55)}$, the algorithms generated in this study can be used to predict the steady-state levels of total and non-specific Se in plasma that will be achieved with any particular regular intake of dietary Se. By this relation, an individual with a plasma se level of $85 \mathrm{ng} / \mathrm{ml}$ would have to consume $1.2 \mu \mathrm{g} \mathrm{Se} / \mathrm{d}$ per $\mathrm{kg}^{0.75}$ to support the plasma total Se level $(106 \mathrm{ng} / \mathrm{ml})$ associated with prostate cancer risk reduction in the NPC Trial ${ }^{(8)}$, whereas an intake of $3.4 \mu \mathrm{g} \mathrm{Se} / \mathrm{d}$ per $\mathrm{kg}^{0.75}$ would be required to reach the plasma total Se level $(147 \mathrm{ng} / \mathrm{ml})$ associated with increased type 2 diabetes risk in the NHANES 2003-4 $4^{(11)}$. This indicates that Se supplementation targeting cancer risk reduction can be safely achieved. 
These results suggest risk categories in which personalised needs for Se can be considered. That women retained ingested Se less well than men suggests that they may have greater dietary Se needs. That the same phenomenon was observed for GPX1 genotype suggests that genotype may also be a determinant of Se need. While the algorithm presented here has application as a general guideline for supplementation, personalised strategies will need to consider the influences of sex and genotype.

\section{Acknowledgements}

We appreciate the contribution of the supplements used in this trial by the Sabinsa Corporation. We gratefully acknowledge the expert contributions of the following members of the Grand Forks Human Nutrition Research Center staff: Brenda Ling for subject recruiting; Wesley Canfield, for subject health oversight; Emily Nielsen, Doreen Rolshoven, Judy Schumacher, and Ruth Christianson, for coordinating subject visits and sample collection; Sandy Botnen, Teresa Numedahl, Wendy Mayer, Pat Wilson and Kay Williams for sample preparation and clinical biochemical analyses; Bonnie Hoverson, Elvira Bell, Sue Sherette, Charlene Kuntz and Doris Zidon and Mary Jo Peltier for preparation and distribution of supplement packets; Laura Idso for sample preparation and enzyme analyses; Eric Uthus for advice on several analytical methods; and Craig Lacher and Bill Martin for Se analyses. The authors' responsibilities were as follows: G. F. C., J. C. W., C. D. D. and J. A. M. designed the research; G. F. C., M. I. J., D. J. W., H. Z., J. I., L. S., A. H., C. S. H., E. C. C. and D. J. W. conducted the research; L. K. J. analysed the data; G. F. C. and M. I. J. wrote the paper and had responsibility for its final content. None of the authors had any competing interests to declare. This research was supported by the Grand Forks Human Nutrition Research Center CRIS project no. 5450-51000-036-00D and NCI-ARS Interagency Agreement 07-0A-5450-330, and Deutsche Forschungsgemeinschaft DFG (Scho849/2-2, GraKo 1208) and Deutsche Krebshilfe (10-1792 Scho2) (to L. S.).

\section{References}

1. Lobanov AV, Hatfield DL \& Gladyshev VN (2009) Eukaryotic selenoproteins and selenoproteomes. Biochim Biophys Acta 1790, 1424-1428.

2. Toppo S, Flohé L, Ursini F, et al. (2009) Catalytic mechanisms and specificities of glutathione peroxidases: variations of a basic scheme. Biochim Biophys Acta 1790, 1486-1500.

3. Duntas LH (2010) Selenium and the thyroid: a close-knit connection. J Clin Endocrinol Metab 95, 5180-5188.

4. Burk RF \& Hill KE (2009) Selenoprotein P-expression, functions, and roles in mammals. Biochim Biophys Acta 1790 , 1441-1447.

5. Shuvalova YA, Kaminnyi AI, Meshkov AN, et al. (2010) Pro198Leu polymorphism of GPx-1 gene and activity of erythrocytic glutathione peroxidase and lipid peroxidation products. Bull Exp Biol Med 149, 743-745.

6. Hu YJ \& Diamond AM (2003) Role of glutathione peroxidase 1 in breast cancer: loss of heterozygosity and allelic differences in the response to selenium. Cancer Res 63, 3347-3351.
7. Clark LC, Combs GF Jr, Turnbull BW, et al. (1996) Effects of selenium supplementation for cancer prevention in patients with carcinoma of the skin. A randomized controlled trial. Nutritional Prevention of Cancer Study Group. J Am Med Assoc 276, 1957-1963.

8. Duffield-Lillico AJ, Dalkin BL, Reid ME, et al. (2003) Selenium supplementation, baseline plasma selenium status and incidence of prostate cancer: an analysis of the complete treatment period of the Nutritional Prevention of Cancer Trial. Br J Urol Int 91, 608-612.

9. Stranges S, Marshall JR, Natarajan R, et al. (2007) Effects of long-term selenium supplementation on type 2 diabetes: A randomized trial. Ann Int Med 147, 217-223.

10. Bleys J, Navas-Acien A \& Gualler E (2007) Serum selenium and diabetes in U.S. adults. Diabetes Care 30, 829-834.

11. Laclaustra M, Navas-Acien A, Stranges S, et al. (2009) Serum selenium concentrations and diabetes in U.S. adults: National Health and Nutrition Examination Survey (NHANES) 2003-2004. Environ Health Perspect 117, 1409-1413.

12. Lipmann SM, Klein EA, Goodman PJ, et al. (2009) Effect of selenium and vitamin $\mathrm{E}$ on risk of prostate and other cancers. J Am Med Assoc 301, 39-51.

13. Chiang EC, Shen S, Kengeri SS, et al. (2009) Defining the optimal selenium dose for prostate cancer risk reduction: Insights from the U-shaped relationship between selenium status, DNA damage, and apoptosis. Dose-Response $\mathbf{8}$, 285-300.

14. Duffield AJ, Thomson CD, Hill CE, et al. (1999) An estimation of selenium requirements for New Zealanders. Am J Clin Nutr 70, 896-903.

15. Broome CS, McArdle F, Kyle JA, et al. (2004) An increase in selenium intake improves immune function and poliovirus handling in adults with marginal selenium status. $A m J$ Clin Nutr 80, 154-162.

16. Burk RF, Norsworthy BK, Hill KE, et al. (2006) Effects of chemical form of selenium on plasma biomarkers in a high-dose human supplementation trial. Cancer Epidemiol Biomarkers Prev 15, 804-810.

17. Xia Y, Hill KE, Byrne DW, et al. (2005) Effectiveness of selenium supplements in a low-selenium area of China. Am J Clin Nutr 81, 829-834.

18. Ravn-Haren G, Krath BN, Overvad K, et al. (2008) Effect of long-term selenium yeast intervention on activity and gene expression of antioxidant and xenobiotic metabolizing enzymes in healthy volunteers from the Danish Prevention of Cancer by Intervention by Selenium (PRECISE) pilot study. Br J Nutr 99, 1190-1198.

19. Wu J, Salisbury C, Graham R, et al. (2009) Increased consumption of wheat biofortified with selenium does not modify biomarkers of cancer risk, oxidative stress, or immune function in healthy Australian males. Environ Mol Mutagen 50, 489-501.

20. Hurst R, Armah CN, Daintry JR, et al. (2009) Establishing optimal selenium status: results of a randomized, doubleblind, placebo-controlled trial. Am J Clin Nutr 91, 921-931.

21. Combs GF Jr, Midthune DN, Patterson KY, et al. (2009) Thyroid hormone levels in subjects supplemented with selenomethionine. Am J Clin Nutr 89, 1-7.

22. Combs GF Jr, Watts JC, Jackson MI, et al. (2011) Determinants of selenium status in healthy adults. Nutr $J \mathbf{1 0}$, 75-82.

23. Suitor CJW, Gardner J \& Willett WC (1989) A comparison of food frequency and diet recall methods in studies of nutrient intake of low-income pregnant women. J Am Diet Assoc 89, 1786-1794. 
24. Paetau I, Rao D, Wiley ER, et al. (1999) Carotenoids in human buccal mucosa cells after 4 wk of supplementation with tomato juice or lycopene supplements. Am J Clin Nutr 70, 490-494.

25. Hu YJ \& Diamond AM (2003) Role of glutathione peroxidase 1 in breast cancer: loss of heterozygosity and allelic differences in the response to selenium. Cancer Res 63, 3347-3351.

26. Villette S, Kyle JAM, Brown KM, et al. (2002) A novel single nucleotide polymorphism in the 3 (untranslated region of human glutathione peroxidase 4 influences lipoxygenase metabolism. Blood Cells Mol Dis 29, 174-178.

27. Méplan C, Crosley LK, Nicol F, et al. (2007) Genetic polymorphisms in the human selenoprotein $\mathrm{P}$ gene determine the response of selenoprotein markers to selenium supplementation in a gender-specific manner (the SELGEN study). FASEB J 21, 3063-3074.

28. Hu YJ, Korotkov KV, Mehta R, et al. (2001) Distribution and functional consequences of nucleotide polymorphisms in the $3^{\prime}$-untranslated region of the human sep15 gene. Cancer Res 61, 2307-2310.

29. Lawrence RA \& Burk RF (1976) Glutathione peroxidase activity in selenium-deficient rat liver. Biochem Biophys Res Commun 71, 952-958.

30. Hollenbach B, Morgenthaler NG, Struck J, et al. (2008) New assay for the measurement of selenoprotein $\mathrm{P}$ as a sepsis biomarker from serum. J Trace Elem Med Biol 22, 24-32.

31. Broderick DJ, Deagen JT \& Whanger PD (1987) Properties of glutathione peroxidase isolated from human plasma. J Inorg Biochem 30, 299-230.

32. Saito Y, Sato N, Hirashima M, et al. (2004) Domain structure of bi-functional selenoprotein P. Biochem J 381, 841-846.

33. Kokarnig S, Kuehnelt D, Stiboller M, et al. (2011) Quantitative determination of small selenium species in human serum by HPLC/ICPMS following a protein-removal, pre-concentration procedure. Anal Bioanal Chem 400, 2323-2327.

34. Waters DJ, Shen S, Glickman LT, et al. (2005) Prostate cancer risk and DNA damage: translational significance of selenium supplementation in a canine model. Carcinogenesis 26, $1256-1262$.

35. Duthie SJ \& Collins AR (1997) The influence of cell growth, detoxifying enzymes and DNA repair on hydrogen peroxidemediated DNA damage (measured using the comet assay) in human cells. Free Radic Biol Med 22, 717-724.

36. Schomburg L \& Schweizer U (2009) Hierarchical regulation of selenoprotein expression and sex-specific effects of selenium. Biochim Biophys Acta 1790, 1453-1462.

37. Méplan C, Crosley LK, Nicol F, et al. (2007) Genetic polymorphisms in the human selenoprotein $\mathrm{P}$ gene determine the response of selenoprotein markers to selenium supplementation in a gender-specific manner (the SELGEN study). FASEB J 21, 3063-3074.

38. Méplan C, Crosley LK, Nicol F, et al. (2008) Functional effects of a common single-nucleotide polymorphism (GPX4c718t) in the glutathione peroxidase 4 gene: interaction with sex. Am J Clin Nutr 87, 1019-1027.

39. Stoedter M, Renko K, Hög A, et al. (2010) Selenium controls the sex-specific immune response and selenoprotein expression during the acute-phase response in mice. Biochem J 429, 43-51.

40. Riese C, Michaelis M, Mentrup B, et al. (2006) Seleniumdependent pre- and posttranscriptional mechanisms are responsible for sexual dimorphic expression of selenoproteins in murine tissues. Endocrinol 147, 5883-5892.

41. Schomburg L, Riese C, Renko K, et al. (2007) Effect of age on sexually dimorphic selenoprotein expression in mice. Biol Chem 388, 1035-1041.

42. Cheng WH, Ho YS, Ross DA, et al. (1997) Cellular glutathione peroxidase knockout mice express normal levels of selenium-dependent plasma and hydroperoxide glutathione peroxidases in various tissues. J Nutr 127, 1445-1450.

43. Cominetti C, de Bartoli MC, Prgatto E, et al. (2011) Associations between glutathione peroxidase-1 Pro198Leu polymorphism, selenium status, and DNA damage in obese women after consumption of Brazil nuts. Nutrition 27, 891-896.

44. Ratnasinghe D, Tangrea JA, Andersen MR, et al. (2000) Glutathione peroxidase codon 198 polymorphism variant increases lung cancer risk. Cancer Res 60, 6381-6383.

45. Hu YJ \& Diamond AM (2003) Role of glutathione peroxidase 1 in breast cancer: loss of heterozygosity and allelic differences in the response to selenium. Cancer Res 63, 3347-3351.

46. Moscow JA, Schmidt L, Ingram DT, et al. (1994) Loss of heterozygosity of the human cytosolic glutathione peroxidase I gene in lung cancer. Carcinogen 15, 2769-2773.

47. Gonzalez S, Huerta JM, Alvarez-Uria J, et al. (2004) Serum selenium is associated with plasma homocysteine concentrations in elderly humans. $J$ Nutr 134, 1736-1740.

48. Hawkes CW \& Keim N (2003) Dietary selenium intake modulates thyroid hormone and energy metabolism in men. J Nutr 133, 3443-3448.

49. Hawkes CW, Keim NL, Richter D, et al. (2008) High-selenium yeast supplementation in free-living North American men: no effect on thyroid hormone metabolism or body composition. J Trace Elem Med Biol 22, 131-142.

50. Lu J, Kaeck M, Jiang C, et al. (1994) Selenite induction of DNA strand breaks and apoptosis in mouse leukemic L1210 cells. Biochem Pharmacol 47, 1531-1535.

51. Sunde RA, Gutzke GE \& Hoekstra WG (1981) Effect of dietary methionine on the biopotency of selenite and selenomethionine in the rat. $J$ Nutr 111, 76-88.

52. Waschulewski IH \& Sunde RA (1998) Effect of dietary methionine on utilization of tissue selenium from dietary selenomethionine for glutathione peroxidase in the rat. J Nutr 118, 367-374

53. Butler JA, Beilstein MA \& Whanger PD (1989) Influence of dietary methionine on the metabolism of selenomethionine in rats. J Nutr 119, 1001-1009.

54. Olson OE, Novachek E, Whitehead E, et al. (1970) Investigations on selenium in wheat. Phytochemistry 9, 1181-1188.

55. Thavarajah D, Vandenberg A, George GN, et al. (2007) Chemical form of selenium in naturally selenium-rich lentils (Lens culinaris L.) from Saskatchewan. J Agric Food Chem 55, 7337-7341. 